\title{
Is There a Speculative Bubble in the Price of Gold?*
}

\author{
Jedrzej P. Bialkowski, Martin T. Bohl’ Patrick M. Stephan and \\ Tomasz P. Wisniewski
}

March 28, 2011

\begin{abstract}
Motivated by the current gold price boom, we investigate whether the rapidly growing investment activities have triggered a new asset price bubble. We draw on the convenience yield model and use commodity dividends to derive gold's fundamental value. Based on the deviations of the actual gold price from its fundamental value, we apply a Markov regime-switching Augmented DickeyFuller test to detect ex post and identify ex ante speculative gold price bubbles. The empirical evidence is favorable for a fundamentally justified price level even during the current period of a drastically rising gold price.
\end{abstract}

JEL Classification: G10, G11, G12, G18

Keywords: Gold Price, Speculative Bubble, Convenience Yield, Markov RegimeSwitching ADF Test

${ }^{*}$ We are indebted to participants of the 15th New Zealand Finance Colloquium in Christchurch, New Zealand, and the research seminar of the Chair of Monetary Economics of the Westphalian Wilhelminian University of Münster, Germany, especially to Philipp Kaufmann, Arne Klein, Judith Lischewski, Jana Riedel, Christian Salm and Michael Schuppli, as well as to Rainer Schüssler for helpful comments and suggestions. We thank Katarina Cohrs and Daniel Simon for excellent research assistance. The paper is accepted for (i) the 2nd Finance and Corporate Governance Conference in Melbourne, Australia (April 28-29, 2011), (ii) the 15th International Conference on Macroeconomic Analysis and International Finance in Rethymno, Greece (May 26-28, 2011), (iii) the 9th Infiniti Conference on International Finance in Dublin, Ireland (June 13-14, 2011), and (iv) the 86th Annual Conference of the Western Economic Association International in San Diego, USA (June 29-July 3, 2011).

${ }^{\dagger}$ Corresponding author: Department of Economics, Westphalian Wilhelminian University of Münster, Am Stadtgraben 9, D-48143 Münster, Germany, Phone: +49 25183 25005, Fax: +49 25183 22846, E-mail address: martin.bohl@wiwi.uni-muenster.de (Martin T. Bohl) 


\section{Introduction and Literature Review}

Between 2001 and early 2011 the price of gold skyrocketed from a level of US\$250 per troy ounce to an all-time high of more than US\$1,400. On the one hand, this development might be fundamentally justified by the increasingly important role of gold as dollar hedge (SjaAstad And Scacciavillani (1996), Capie ET Al. (2005), PukThuanthong And Roll (2011)), inflation hedge (Blose (2010) and the references therein) and safe haven (HILlier ET AL. (2006), BAur AND LuCEy (2010), BAuR AND MCDermott (2010)). On the other hand, gold's growing attractiveness as an investment and the extraordinary gold price increase might indicate a speculative bubble. Phillips AND Yu (2010) find evidence for a speculative bubble moving from the equity market (up to 2000) over the US housing market (up to 2007) to the crude oil market (up to mid-2008). Thus, we ask whether the gold market is another victim of such a wandering asset price bubble. If this is indeed the case, gold market participants will run the risk of experiencing huge losses once the bubble bursts. So far, to the best of our knowledge, the possibility that the gold price may currently exhibit a speculative bubble has not been investigated in the academic literature. The present paper aims to fill this gap by applying an econometric technique which allows for early detection of speculative bubbles. Thus, we are able to offer insights not only for academics and investors, but also for decision makers engaged to fight speculative bubbles by framing early monetary policy responses or other regulatory interventions.

While speculative bubbles in stock prices have been intensively studied in the literature, only a few articles analyze speculative bubbles in the gold price. Among these papers, DiBA AND Grossman (1984) investigate the stationarity properties of the real gold price for the time period from 1975 to 1983 using conventional unit-root and cointegration tests. They conclude that the price process is entirely based on market fundamentals. As shown by EvAns (1991), however, the conventional unit-root and cointegration tests do not allow to detect the important class of periodically bursting bubbles. Due to the bursting nature of such bubbles, such tests have a tendency to reject the null hypothesis of non-stationarity in favor of the stationary hypothesis much 
too often. Furthermore, Charemza And Deadman (1995) argue that the misleading nature of unit root testing also holds for the less restrictive class of speculative bubbles with stochastic explosive roots, casting further doubts on the results of DIBA And Grossman (1984). Being aware of this critique, PIndycK (1993) draws on the convenience yield model, and calculates gold's fundamental value based on the present value model. Running tests of forecasting power, Granger causality tests and tests of restrictions of appropriately specified vector autoregressive (VAR) models, PINDYCK (1993) finds evidence in favor of a gold price bubble somewhere between 1975 and 1990. Finally, Went ET AL. (2009) also build on the convenience yield model, and run the duration dependence test which indicates a gold price bubble somewhere in the time span from 1976 to 2005.

Even though PindyCK's (1993) and WENT ET AL.'s (2009) approaches are methodologically valid, their results suffer from the fact that they do not indicate when exactly the gold price may have been in the bubble phase. In order to overcome this shortcoming, we stick to the convenience yield and the present value model, but then apply a Markov regime-switching Augmented Dickey-Fuller (ADF) test. Based on estimated probabilities of being in the bubble and the non-bubble regime, this approach also allows us to detect a speculative bubble during the recent period of a drastically rising gold price, even if it is still in its initial phase. We are in line with some other methods which are also able to date stamp the origination and collapse of speculative bubbles. The smooth-transition model applied by MCMillan (2007) draws on estimated transition functions; the supplemented ADF test proposed by PHILliPS ET AL. (2011) and extended by PHILLIPS AND YU (2010) rests on forward recursive regressions; and the unobserved-component approach introduced by Wu (1997) and extended by ALAnaswah And Wilfling (2011) makes use of a state-space model and the Kalman filtering technique.

The paper proceeds as follows. In SECTION 2, the construction of gold's fundamental value is discussed, and the data is presented. SECTION 3 introduces the Markov regimeswitching ADF test, and shows its ability to detect periodically bursting bubbles. In Section 4, empirical results are presented and discussed. SECTion 5 concludes. 


\section{Construction of Gold's Fundamental Value and Data}

Since speculative bubbles are not observable per se, testing for them mainly requires to approximate the fundamental value of the underlying asset. In terms of storable commodities such as gold, the standard way of doing so is to make use of the convenience yield model (PINDYCK (1993)). ${ }^{1}$ The term convenience yield refers to the benefits the holder of the physical raw material experiences relative to the owner of a future contract written on the respective asset. The convenience yield model is based on the non-arbitrage-condition:

$$
F_{t}^{T}=P_{t} \cdot e^{\left(r_{f}-c y_{t}\right)(T-t)}
$$

$F_{t}^{T}$ is the price of the future with maturity $T$ at time $t, P_{t}$ denotes the commodity's spot price, $r_{f}$ represents the risk-free interest rate, and $c y_{t}$ stands for the net convenience yield rate. ${ }^{2}$ Eq. (1) states that under no arbitrage the future price must equal the spot price adjusted by the opportunity costs and the benefits of holding the physical commodity. The term $\left(r_{f}-c y_{t}\right)$ is, thus, also called cost of carry. Put differently, investing borrowed money only and taking no risk necessarily lead to a terminal wealth of 0 .

Although the owner of the storable raw material, of course, does not receive any cash flows over the interval $(t, t+d t)$, according to GEMAN (2009), the monetary value of the commodity dividend, $D_{t+d t}$, can be approximated by:

$$
D_{t+d t}=P_{t} \cdot c y_{t} \cdot d t .
$$

\footnotetext{
${ }^{1}$ Given gold's role as dollar hedge, inflation hedge and safe haven, we also experiment to approximate the fundamental value by relating the gold price to possible influencing factors such as the trade-weighted value of the US dollar against other major currencies (effective exchange rate), (world and US) consumer prices and financial indicators like the MSCI world index and the US Treasury bill rate. Unfortunately, however, we are unable to establish a stable long-run relationship between them, so that we end up with the convenience yield model as our preferential option to proceed. In order to understand why these macroeconomic and financial indicators are not cointegrated with the gold price in our sample, note that in the case of the MSCI world index, for instance, it has risen over the last two years largely in line with the gold price, questioning the usually negative relationship. Furthermore, according to CHAN ET AL. (2011), gold is negatively related to bonds and stocks in tranquil periods, but not in times of crisis when there is no and even positive correlation, respectively.

${ }^{2}$ The net convenience yield denotes the difference between the pure benefits of holding the physical commodity (i.e., the gross convenience yield) and the efforts of storing it (i.e., the warehousing costs).
} 
Since we do not require the net convenience yield rate to be non-negative, the commodity dividend can take any value above or below 0 as well. Obviously, this is in contrast to stock dividends. The sign of the net convenience yield rate primarily depends on the type of raw material, its level of inventory and the period under investigation. ${ }^{3}$

In order to calculate the net convenience yield rate for gold, we are in need of continuous future and spot price time series as well as a proxy for the risk-free interest rate. Daily future prices used here are for contracts traded on the Commodities Exchange (COMEX) division of the New York Mercantile Exchange (NYMEX), and date back until November 1978. ${ }^{4}$ Applying the first-day-of-delivery-month criterion, we always draw on the first-nearby contract, and switch to the second-nearby on the first day of the first-nearby's delivery month. ${ }^{5}$ The reason to switch sufficiently prior to the expiration of the first-nearby is that the latter runs out of liquidity close to maturity. Alternatively, we experiment with switching once the second-nearby always exhibits a higher open interest than the first-nearby, following the liquidity-peak criterion. ${ }^{6}$ In contrast to future prices, daily spot prices already are available as a continuous time series. ${ }^{7}$ Finally, the risk-free interest rate is approximated by the mean of the threemonths US Treasury bill interest rate between November 1978 and March 2010. ${ }^{8}$ All time series are taken from Thomson Reuters Datastream, and are quoted in US\$ per troy ounce except for the interest rate which is quoted in percent p.a.

\footnotetext{
${ }^{3}$ Note that the commodity dividend, of course, is also influenced by the gold price itself which is critical since the latter might be blown up by the speculative bubble. However, when using the convenience yield and the present value model to test for speculative bubbles, this possible drawback needs to be accepted since, in contrast to stock dividends, commodity dividiends are not observable per se.

${ }^{4}$ The COMEX began to offer trading in gold future contracts already at the end of 1974 . However, for the first four years of trading Thomson REuters DATASTREAM does not provide any data.

${ }^{5}$ Note that the COMEX data set contains several extremely short-running contracts which are characterized by very small open interest. In order to avoid any distortions of our continuous time series due to thin trading, we simply ignore these contracts.

${ }^{6}$ Note, however, that regardless of the roll criterion applied, we do not expect to find significant differences between the resulting future price time series (CARCHANO AND PARDO (2009)).

${ }^{7}$ Alternatively, we also experiment with a spot price time series derived from the price and the maturity of the first- and the second-nearby contract. The reason for doing so is to avoid possible distortions of the actual spot price time series due to discounts and premiums that result from longstanding relationships between buyers and sellers (PINDYCK (1993)). Under the bottom line, however, results are robust against using the alternative spot price time series.

${ }^{8}$ Alternatively, we also experiment with a time-varying risk-free interest rate, but find that results are qualitatively similar to the case of a constant rate.
} 
The net convenience yield rate is, then, plugged into eq. (2), so that daily commodity dividends can be obtained. ${ }^{9}$ Afterwards, we aggregate the latter over all trading days of the respective month, ending up with $T=377$ data points (from November 1978 to March 2010). Figure 1 (nominal data) and 2 (real data) show the resulting dividend time series based on the first-day-of-delivery-month criterion together with the endof-month spot price time series. Since both time series generally move in the same direction, a stable long-run relationship seems to be present.

[FIgURE 1 and 2 about here]

In order to establish a stable long-run relationship between the gold price and the commodity dividend, we apply the Engle-Granger methodology. We, first, analyze the stationarity properties of the single time series in logarithms, $\ln \left(P_{t}\right)$ and $\ln \left(D_{t}\right)$, making use of the ADF test and the Kwiatkowski-Phillips-Schmidt-Shin (KPSS) test. ${ }^{10}$ If both time series are integrated of the same order, we move on by running a simple ordinary least squares (OLS) regression of $\ln \left(P_{t}\right)$ on $\ln \left(D_{t}\right)$. The long-run relationship, thus, reads:

$$
\ln \left(P_{t}\right)=\alpha+\beta \cdot \ln \left(D_{t}\right)+u_{t}
$$

where $u_{t}$ represents the error term. Alternatively, we also deflate the spot price and the commodity dividend using the US consumer price index, ensure that the logarithms of both time series are still integrated of the same order, and re-run the regression (3). ${ }^{11}$ Regardless of using nominal or real data, we expect $\beta$ to be positive. Finally, we interpret the residuals as the deviation of the gold price from its fundamental value, $F V_{t}$, which is given by $F V_{t}=e^{\widehat{\alpha}+\widehat{\beta} \cdot \ln \left(D_{t}\right)}$.

\footnotetext{
${ }^{9}$ Therefore, we set $d t=1 / 250=0.004$, assuming that one year has approximately 250 trading days, which is a common rule of thumb.

${ }^{10}$ In line with the literature, we decide to use logs to reduce the impact of outliers. This is possible since all commodity dividends are positive except one. The latter is, thus, omitted from the further analysis.

${ }^{11}$ Deflating both time series is done by multiplying with the price index of March 2010 and dividing by that one of the respective month, so that the respective data point for March 2010 is identical in both nominal and real terms.
} 


\section{Markov Regime-Switching ADF Test for Bubble Detection}

\subsection{Test Approach}

Based on the long-run relationship between the gold price and the commodity dividend, we test for speculative bubbles in the former, extending the ordinary ADF equation to a standard Markov regime-switching model. In the literature, this approach has mostly been carried out to analyze directly the stationarity properties of the time series under investigation (Funke ET AL. (1994), HALL ET AL. (1999)). By contrast, we propose to use the Markov regime-switching ADF test with respect to the residuals of the longrun relationship (3). The main advantage of the latter option is that it does not rest on an informal comparison of the switching patterns of different time series, but allows for solid statistical inference. If periodically bursting bubbles exist, we should be able to distinguish between a moderately growing regime on the one hand and an explosive and then collapsing regime on the other hand. ${ }^{12}$

Our two-state first-order Markov regime-switching ADF equation reads:

$$
\Delta u_{t}=\rho_{0, S_{t}}+\rho_{1, S_{t}} \cdot u_{t-1}+\sum_{k=1}^{p} \beta_{k, S_{t}} \cdot \Delta u_{t-k}+\varepsilon_{S_{t}},
$$

where $\Delta$ stands for the first difference, $S_{t}=(0,1)$ is the stochastic regime variable, $\psi \equiv\left(\rho_{0, S_{t}}, \rho_{1, S_{t}}, \beta_{k, S_{t}}\right)^{\prime}$, with $k=1, \ldots, p$, are the regression coefficients, and $\varepsilon_{S_{t}} \stackrel{\text { i.i.d. }}{\sim}$ $N\left(0, \sigma_{S_{t}}^{2}\right)$ represents the error term. ${ }^{13}$ If we are able to distinguish between a bubble and a non-bubble regime, we will obtain one $\rho_{1, i}, i \in[0 ; 1]$, which is statistically significantly bigger than 0 (so that regime $i$ is explosive and then collapsing), and another $\rho_{1, j}, j=(1-i)$, which is statistically significantly smaller than 0 (so that regime $j$ is stationary). In order to ensure that the error terms are serially uncorrelated,

\footnotetext{
${ }^{12}$ Note that Markov regime-switching models may indicate different regimes even though there are no structural breaks in the data. Thus, we, first, apply an ordinary ADF test to the residuals of the long-run relationship, and test the stability of the ADF coefficient making use of the Quandt-Andrews unknown breakpoint tests (the supremum, exponential and average likelihood ratio test).

${ }^{13}$ Statistical significance is judged based on critical values obtained by using a parametric bootstrap algorithm (PSARADAKIS (1998)). Furthermore, we allow for regime-varying volatility as well since, under the constant variance assumption, we run into danger that varied volatilities across regimes will be absorbed by the ADF coefficients, which may lead to a misjudgement of speculative bubbles (SHI ET AL. (2010)).
} 
the optimal lag length, $p$, is determined by starting with $p_{\max }=\left[T^{(1 / 3)}\right]$, where [.] denotes the integer part of its argument, and then reducing the model until the first lagged residual difference has a statistically significant influence at the $5 \%$ level in at least one regime. Since the probability of $S_{t}$ being either 0 or 1 depends on the past only through the most recent regime $S_{t-1}$, the transition probabilities are defined by $p_{00} \equiv \operatorname{Pr}\left(S_{t}=0 \mid S_{t-1}=0\right)$ and $p_{11} \equiv \operatorname{Pr}\left(S_{t}=1 \mid S_{t-1}=1\right) .{ }^{14}$ Finally, we collect all unknown parameters in the vector $\theta \equiv\left(\psi, \sigma_{S_{t}}^{2}, p_{00}, p_{11}\right)^{\prime}$.

In order to estimate $\theta$, we draw on the expectation-maximization (EM) algorithm which is an iterative procedure that consists of two steps: the expectation step and the maximization step (Hamilton (1994), Kim AND Nelson (2000)). In the expectation step, we estimate the filter probabilities, $\operatorname{Pr}\left(S_{t}=i \mid u_{t}, \ldots, u_{1} ; \theta\right)$, and the smoothed probabilities, $\operatorname{Pr}\left(S_{t}=i \mid u_{T}, \ldots, u_{1} ; \theta\right)$, of being in the two regimes, using the estimate of $\theta$ from the previous iteration step. In the maximization step, we, then, draw on these probabilities to improve our estimate of $\theta$ based on the maximum-likelihood (ML) approach. Given our model in eq. (4), however, we need not maximize the log likelihood function numerically, but are able to obtain a closed-form solution for $\theta$. Furthermore, the EM algorithm is relatively robust with respect to poorly chosen starting values for $\theta$, quickly moving to a reasonable region of the likelihood surface.

\subsection{Evaluation of the Test}

In order to show the ability of our Markov regime-switching ADF test to detect periodically bursting bubbles, we make use of EvAns (1991). We employ the standard present value model for stock prices with constant expected returns:

$$
P_{t}=\frac{1}{1+r} E_{t}\left(P_{t+1}+D_{t+1}\right)
$$

where $P_{t}$ is the real stock price at time $t, 0<1 /(1+r)<1$ denotes the constant discount factor, $E_{t}(\cdot)$ stands for the expectations conditional on information at time $t$, and $D_{t+1}$ measures the real dividend paid to the owner of the stock between $t$ and

\footnotetext{
${ }^{14}$ Alternatively, we also use time-varying transition probabilities drawing on the effective exchange rate of the US dollar, (world and US) consumer prices and financial indicators as exogenous variables (Diebold ET AL. (1994)). However, results are qualitatively the same as in the case of constant transition probabilities.
} 
$(t+1)$. Given that the transversality condition holds true, the stock's fundamental value, $F V_{t}$, follows from eq. (5) as:

$$
F V_{t}=\sum_{i=1}^{\infty}\left(\frac{1}{1+r}\right)^{i} E_{t}\left(D_{t+i}\right)
$$

The general solution to eq. (5) is:

$$
P_{t}=F V_{t}+B_{t}
$$

where $B_{t}$ denotes the rational bubble which satisfies the submartingal condition:

$$
B_{t}=\frac{1}{1+r} E_{t}\left(B_{t+1}\right)
$$

Real dividends are assumed to be generated as a random walk with drift, $\mu$ :

$$
D_{t}=\mu+D_{t-1}+u_{t}
$$

where $u_{t} \stackrel{\text { i.i.d. }}{\sim} N\left(0, \sigma^{2}\right)$. In line with EVANS (1991), we set $\mu=0.0373, \sigma^{2}=0.1574$ and $D_{0}=1.3$, which belong to the actual dividend process for the S\&P 500 sample covering the time period from 1871 to 1980. Furthermore, we choose $T=100$. With dividends generated by eq. (9), eq. (6) can be solved to yield:

$$
F V_{t}=\frac{1+r}{r^{2}} \mu+\frac{1}{r} D_{t}
$$

where we set $r=0.05$. Finally, periodically bursting bubbles are specified by:

$$
B_{t}= \begin{cases}(1+r) B_{t-1} v_{t} & \text { if } B_{t-1} \leq \alpha \\ \left(\delta+\frac{1+r}{\pi}\left(B_{t-1}-\frac{\delta}{1+r}\right) \xi_{t}\right) v_{t} & \text { if } B_{t-1}>\alpha\end{cases}
$$

where $\alpha$ and $\delta$ are scalars with $0<\delta<(1+r) \alpha, \xi_{t}$ is an i.i.d. Bernoulli process with $\operatorname{Pr}\left(\xi_{t}=0\right)=(1-\pi)$ and $\operatorname{Pr}\left(\xi_{t}=1\right)=\pi$, and $v_{t}$ is an i.i.d. positive random variable with $E_{t-1}\left(v_{t}\right)=1$, which is independent of $\xi_{t}$. Setting $\pi$ and $\xi_{t}$ equal to unity shows that the equation for $B_{t-1} \leq \alpha$ (i.e., the first regime) is a special case of the equation for $B_{t-1}>\alpha$ (i.e., the second regime). Note that the bubble process in eq. (11) satisfies eq. (8), and that $B_{t}>0$ implies $B_{s}>0$ for all $s>t$. As long as $B_{t} \leq \alpha$, the bubble grows at mean rate $(1+r)$. When eventually $B_{t}>\alpha$, it grows at the faster mean rate 
$(1+r) / \pi$ as long as the eruption continues, but collapses with probability $(1-\pi)$ in each period. When the bubble collapses, it falls to a mean value of $\delta$, and the process starts again. In line with Evans (1991), we set $\alpha=1, \delta=B_{0}=0.5$, and $\pi=0.85$. $v_{t}$ is chosen to be i.i.d. lognormal, scaled to have unit mean; that is $v_{t}=e^{y_{t}-\tau^{2} / 2}$, where $y_{t} \stackrel{\text { i.i.d. }}{\sim} N\left(0, \tau^{2}\right)$. For the simulation, we set $\tau=0.05$.

The bubble time series generated is scaled up by a factor of 20 , so that the sample variance of $\Delta B_{t}$ is many times the sample variance of $\Delta F V_{t}$, and then added to the fundamental value according to eq. (7). One possible realisation of the respective time series for $F V_{t}$ and $P_{t}$ is shown in the upper part of Figure 3. Afterwards, we apply our battery of unit root tests to ensure that $P_{t}$ is $I(1)$. Running the regression in eq. (3) of $P_{t}$ on $D_{t}$ results in residuals which, for our exemplary simulation, are displayed in the middle part of Figure 3. Finally, we use these residuals for our Markov regimeswitching ADF test from eq. (4), and obtain (filter and) smoothed probabilities. Based on our exemplary simulation, these smoothed probabilities look as shown in the lower part of Figure 3.

[FIGURE 3 about here]

Even without any detailed discussion of the regression results, we clearly see that our Markov regime-switching ADF test is able to detect the periodically bursting bubbles generated. The periods of explosive and then collapsing bubbles are characterized by substantial deviations of the price time series from its fundamental value, i.e., strongly positive residuals, and easily identifiable regime switches, visualized by the smoothed probabilities (see the grey-shaded areas). Repeating this simulation exercise some thousand times, in the vast majority of cases, we obtain one $\rho_{1, i}, i \in[0 ; 1]$, from eq. (4), which is statistically significantly bigger than 0 , and another $\rho_{1, j}, j=(1-i)$, which is statistically significantly smaller. This is perfectly in line with our expectations since the explosive and then collapsing regime should be characterized by an explosive root, while the moderately growing regime should be stationary. In contrast, as shown by Evans (1991), the ordinary ADF test performs very poorly in the presence of periodically bursting bubbles. Apart from that, the transition probability of the stationary 
regime is always much bigger and the variance of the error term is much smaller when compared to the explosive and then collapsing regime. ${ }^{15}$ Put differently, the latter is extremely unstable and of short duration. ${ }^{16}$

\section{Empirical Results}

As outlined in SECTION 2, we start our empirical analysis by applying a battery of unit root tests to the log gold price and the log commodity dividend time series. With reference to the results shown in Panel (A) of TABLE 1, the tests indicate that, regardless of whether we consider nominal or real data, both variables are $I(1)$. According to the Engle-Granger methodology, we regress the log gold price on the log commodity dividend as in eq. (3), establishing a long-run relationship. Panel (B) of TABLE 1 shows the results of the OLS regression for both nominal and real data.

[TABLE 1 about here]

In both cases, the log commodity dividend explains more than half of the variance of the log gold price, and the slope parameter is positive as expected. With focus on the nominal (real) data, it implies that once the commodity dividend increases by one percent, the gold price goes up by 0.61 (0.76) percent. Using the OLS estimates, we calculate gold's fundamental value. Figure 4 (nominal data) and 5 (real data) show the resulting time series in comparison to the log gold price. It indicates that even though the fundamental value is more volatile than the log gold price, both times series generally move together.

[FIgURE 4 and 5 about here]

\footnotetext{
${ }^{15}$ Note that a regime's mean duration is simply given by $1 /\left(1-p_{i i}\right), i \in[0 ; 1]$.

${ }^{16}$ Apart from this simulation exercise, we also apply our Markov regime-switching ADF test to the residuals of a regression of the (nominal and real) S\&P 500 stock price index on the corresponding S\&P 500 composite dividends (or earnings) for different time windows, always covering the well-established dotcom bubble (not reported, but available from the authors upon request). The necessary data are taken from the website of Robert J. Shiller (http://aida.econ.yale.edu/ shiller). Being again able to distinguish between a stationary and an explosive and then collapsing regime shows that using our Markov regime-switching ADF test is suitable not only in the case of artifical data, but also when it is confronted with real world questions.
} 
Next, the residuals of the long-run relationship are used to run our Markov regimeswitching ADF test from eq. (4). ${ }^{17}$ TABLE 2 shows the results obtained by applying the EM algorithm. ${ }^{18}$ For both nominal and real data, lagged residual differences have a statistically significant influence in one regime only. More importantly, for both nominal and real data, we see that on the one hand $\widehat{\rho}_{1,0}$ is statistically significantly smaller than 0 , so that regime 0 is stationary (left-tailed ADF test). On the other hand, for speculative bubbles to be present, regime 1 then needs not only to be instationary, but truly explosive. To see if this is the case, we move on by testing whether $\widehat{\rho}_{1,1}$ is statistically significantly bigger than 0 (right-tailed ADF test). As shown by TABLE 2, however, regime 1 is characterized by a unit root, but not by explosiveness. Based on our Markov regime-switching ADF test, speculative bubbles, thus, cannot be detected in the gold price.

\section{[TABLE 2 about here]}

Finally, we are interested when exactly the long-run relationship between the gold price and the commodity dividend may have been broken, and run statistical inference of being in the two regimes. FIGURE 6 (nominal data) and 7 (real data) show the filter and the smoothed probabilities in comparison to the residuals of the long-run relationship. As is obvious, during the time span from 1979 to 1982, residuals are strongly positive, and we are in the unit root regime. For the rest of the period under investigation, however, residuals fluctuate around 0 , and we are in the stationary regime. Even though at the end of our sample, at least in the nominal case, residuals are again persistently positive, the magnitude is not comparable to those from the beginning of the time series, and we, thus, do not switch back to the unit root regime.

\section{[FiguRE 6 and 7 about here]}

\footnotetext{
${ }^{17}$ Note that the Quandt-Andrews unknown breakpoint tests indicate a structural break in the ADF coefficient of the ordinary ADF test for both nominal and real data (not reported, but available from the authors upon request), so that using a Markov regime-switching model is valid.

${ }^{18}$ For computational convenience, convergence of the EM algorithm is said to be reached as soon as the value of the $\log$ likelihood function does not increase by more than 1/1,000,000 anymore. Furthermore, we try several different sets of randomly chosen starting values and choose that one which leads to the highest value of the log likelihood function.
} 


\section{Conclusion}

Motivated by the current gold price boom, this paper focusses on whether the rapidly growing investment activities have caused a new asset price bubble. Drawing on the convenience yield model, we approximate the commodity dividends with the help of future contracts, and use them to explain the gold price, establishing a stable long-run relationship. Based on the residuals of this regression, we apply a Markov regimeswitching ADF test. As shown by a simulation exercise, this test is able to detect speculative bubbles. However, neither for the gold price boom from 1979 to 1982 nor at the end of our sample can we find any evidence of speculative bubbles using this methodology.

The most likely explanation for our results is that three decades ago, skyrocketing inflation (caused by the second oil crisis and amplified by a very expansive monetary and fiscal policy) and geopolitical turmoil (especially due to the start of the Iran-Iraq war and the Soviet invasion of Afghanistan) caused financial market participants to look for stable investments in unstable times. Similarly, many investors have fled to gold as a safe haven in times of the recent world financial and the Greek sovereign debt crisis, causing excess demand and the corresponding price surge. Furthermore, given a very expansive monetary policy especially in the US, financial market participants expect both high future inflation and a weakening of the US dollar. Since gold is seen as a globally accepted currency which does not lose its purchasing power, they may have expanded its portfolio weight significantly.

Scope for future research is given by applying the convenience yield model and our Markov regime-switching ADF test to other commodities which have recently been blamed for exhibiting speculative bubbles as well. Up to 2008, for instance, the price of crude oil and many other raw materials skyrocketed to new all-time highs, but then suddenly collapsed during few weeks. Furthermore, over the last couple of months, the risk of new speculative bubbles especially in foodstuff, ranging from cocoa over sugar to wheat, has been emphasized by part of the financial press. Running solid statistical inference could, thus, contribute to calm the discussion about whether speculators, 
driving commodity prices to dizzying heights, are really responsible for food shortages in developing countries. Additionally, it would provide financial market participants with valuable information for their investment decisions, since not only precious metals such as gold, but also many other commodities have gained substantial interest by investors over the last couple of years. 


\section{References}

Al-Anaswah, N. and Wilfling, B. (2011). Identification of Speculative Bubbles using State-Space Models with Markov-Switching. Journal of Banking and Finance, forthcoming.

Baur, D. G. and Lucey, B. M. (2010). Is Gold a Hedge or a Safe Haven? An Analysis of Stocks, Bonds and Gold. Financial Review, 45(2):217-229.

Baur, D. G. and McDermott, T. K. (2010). Is Gold a Safe Haven? International Evidence. Journal of Banking and Finance, 34(8):1886-1898.

Blose, L. E. (2010). Gold Prices, Cost of Carry, and Expected Inflation. Journal of Economics and Business, 62(1):35-47.

Capie, F., Mills, T. C., and Wood, G. (2005). Gold as a Hedge against the Dollar. Journal of International Financial Markets, Institutions and Money, 15(4):343-352.

Carchano, O. and Pardo, A. (2009). Rolling Over Stock Index Futures Contracts. Journal of Futures Markets, 29(7):684-694.

Chan, K. F., Treepongkaruna, S., Brooks, R., and Gray, S. (2011). Asset Market Linkages: Evidence from Financial, Commodity and Real Estate Assets. Journal of Banking and Finance, forthcoming.

Charemza, W. W. and Deadman, D. F. (1995). Speculative Bubbles with Stochastic Explosive Roots: The Failure of Unit Root Testing. Journal of Empirical Finance, $2(2): 153-163$.

Diba, B. T. and Grossman, H. I. (1984). Rational Bubbles in the Price of Gold. NBER (Cambridge, MA) Working Paper No. 1300.

Diebold, F. X., Lee, J.-H., and Weinbach, G. C. (1994). Regime Switching with Timevarying Transition Probabilities. Nonstationary Time Series Analysis and Cointegration, C. Hargreaves (ed.), Oxford: Oxford University Press, 283-302. 
Evans, G. W. (1991). Pitfalls in Testing for Explosive Bubbles in Asset Prices. American Economic Review, 81(4):922-930.

Funke, M., Hall, S. G., and Sola, M. (1994). Rational Bubbles during Poland's Hyperinflation - Implications and Empirical Evidence. European Economic Review, 38(6):1257-1276.

Geman, H. (2009). Commodities and Commodity Derivatives. Chichester: Wiley.

Hall, S. G., Psaradakis, Z., and Sola, M. (1999). Detecting Periodically Collapsing Bubbles: A Markov-Switching Unit Root Test. Journal of Applied Econometrics, $14(2): 143-154$.

Hamilton, J. D. (1994). Time Series Analysis. Princeton, NJ: Princeton University Press.

Hillier, D., Draper, P., and Faff, R. (2006). Do Precious Metals Shine? An Investment Perspective. Financial Analysts Journal, 62(2):98-106.

Kim, C. J. and Nelson, C. R. (2000). State Space Models with Regime Switching. Cambridge, MA: MIT Press.

McMillan, D. G. (2007). Bubbles in the Dividend-Price Ratio? Evidence from an Asymmetric Exponential Smooth-Transition Model. Journal of Banking and Finance, $31(3): 787-804$.

Phillips, P. C. B., Wu, Y., and Yu, J. (2011). Explosive Behavior in the 1990s Nasdaq: When Did Exuberance Escalate Asset Values? International Economic Review, $52(1): 201-226$.

Phillips, P. C. B. and Yu, J. (2010). Dating the Timeline of Financial Bubbles During the Subprime Crisis. Cowles Foundation Discussion Paper No. 1770.

Pindyck, R. S. (1993). The Present Value Model of Rational Commodity Pricing. Economic Journal, 103(418):511-530. 
Psaradakis, Z. (1998). Bootstrap-based Evaluation of Markov-Switching Time Series Models. Econometric Reviews, 17(3):275-288.

Pukthuanthong, K. and Roll, R. (2011). Gold and the Dollar (and the Euro, Pound, and Yen). Journal of Banking and Finance, forthcoming.

Shi, S.-P., Phillips, P. C. B., and Yu, J. (2010). Testing for Periodically Collapsing Bubbles: An Generalized Sup ADF Test. Working Paper.

Sjaastad, L. A. and Scacciavillani, F. (1996). The Price of Gold and the Exchange Rate. Journal of International Money and Finance, 15(6):879-897.

Went, P., Jirasakuldech, B., and Emekter, R. (2009). Bubbles in Commodities Markets. SSRN Working Paper.

Wu, Y. (1997). Rational Bubbles in the Stock Market: Accounting for the US StockPrice Volatility. Economic Inquiry, 35(2):309-319. 
Figure 1: Nominal spot price and convenience yield

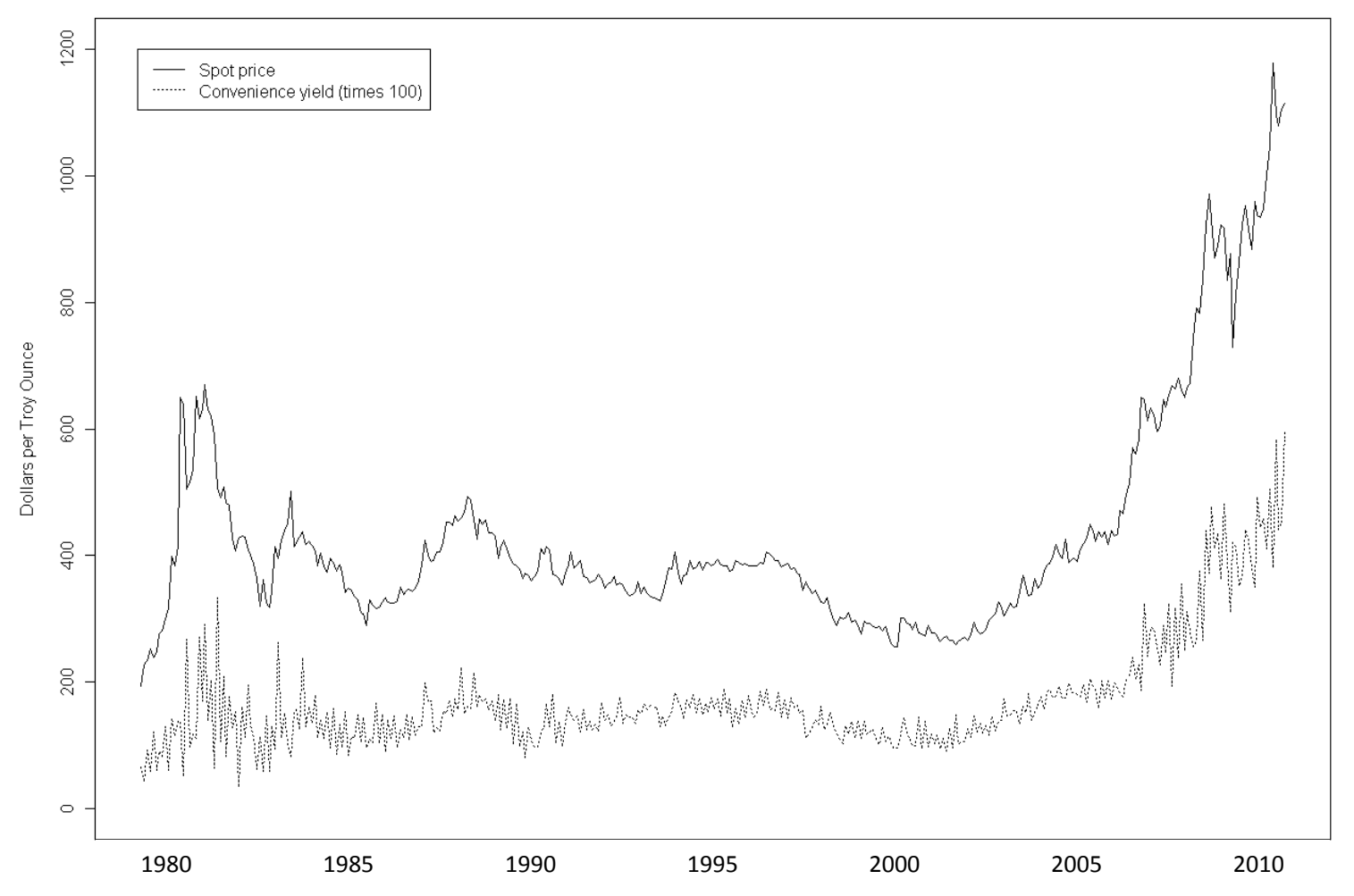

Note: The convenience yield time series is based on the first-day-of-delivery-month criterion with the understanding that results are qualitatively the same once we use the liquidity-peak criterion. 
Figure 2: Real spot price and convenience yield

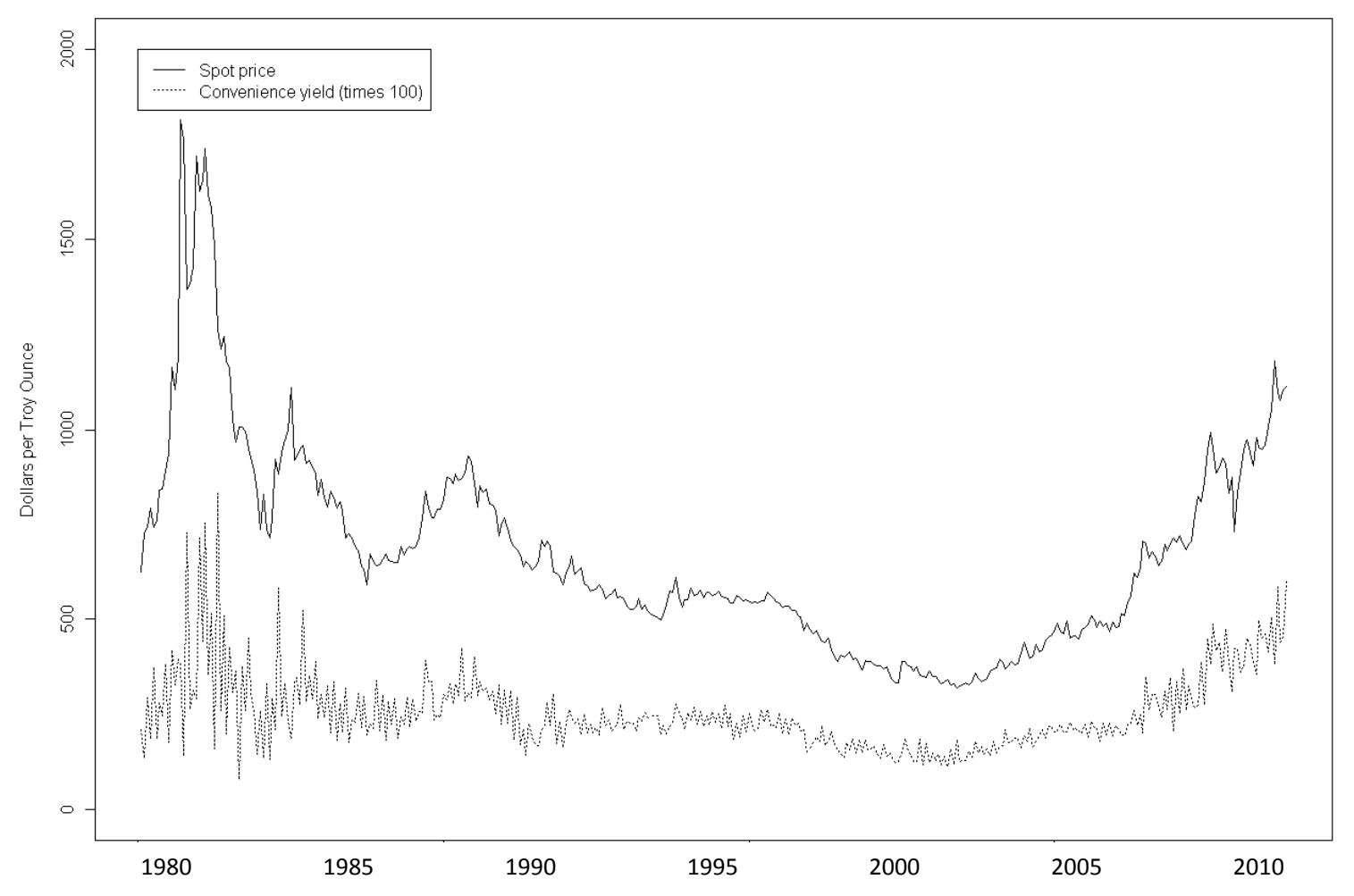

Note: The convenience yield time series is based on the first-day-of-delivery-month criterion with the understanding that results are qualitatively the same once we use the liquidity-peak criterion. 
Figure 3: Results of one typical simulation run

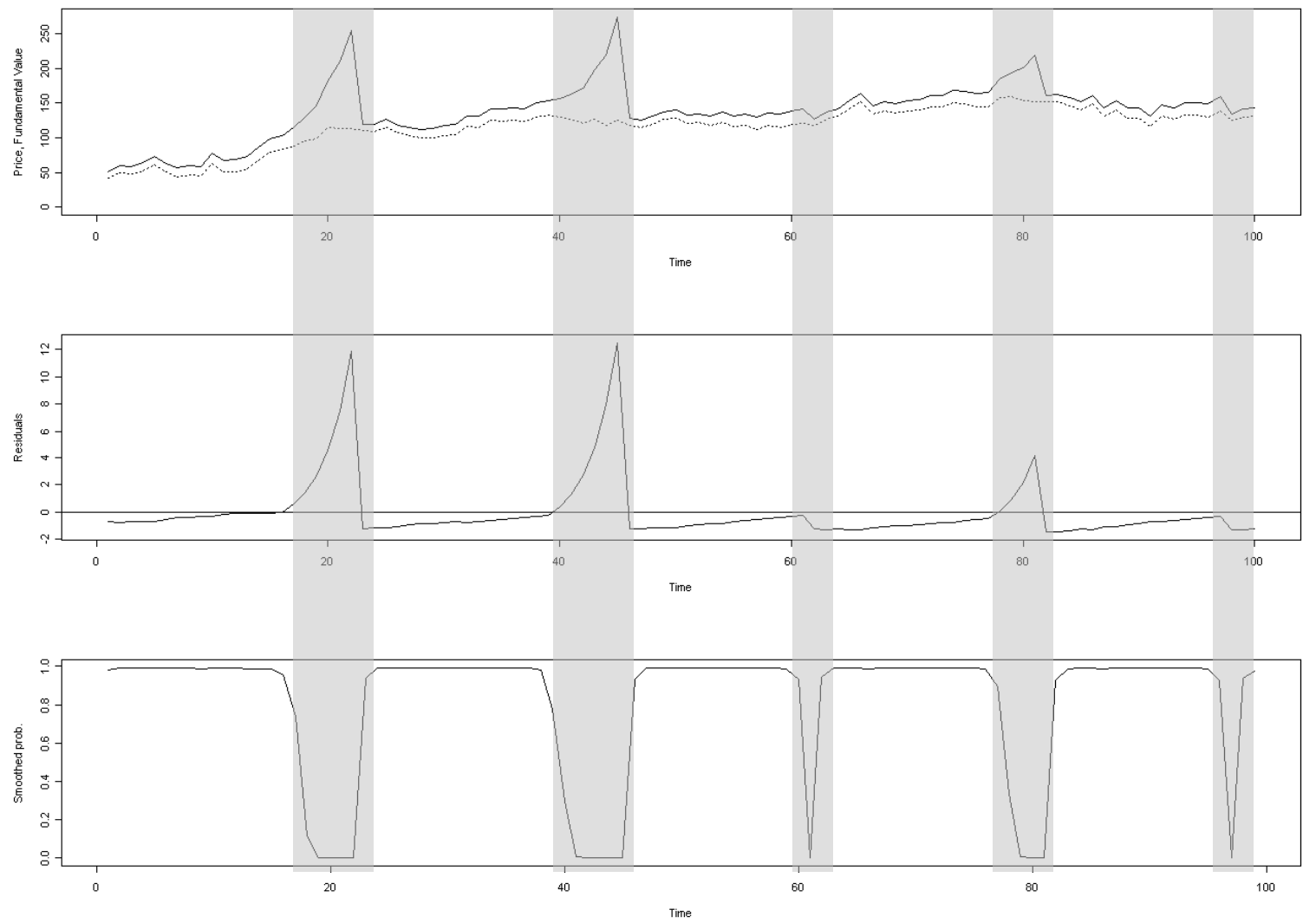

Notes: In the upper part, one possible realization of the price time series and the fundamental value is shown. The fundamental value is obtained by using eq. (10) which, in turn, is based on the dividend process in eq. (9). The price time series is, then, calculated by summing the fundamental value and the bubble time series which is generated by eq. (11) and scaled up by a factor of 20 . In the middle part, the residuals from the regression of this price time series on the corresponding dividend process are shown. Using these residuals, in the lower part, the smoothed probabilities based on the ML estimates from the model in eq. (4) are shown. 
Figure 4: Nominal spot price and fundamental value (in logs)

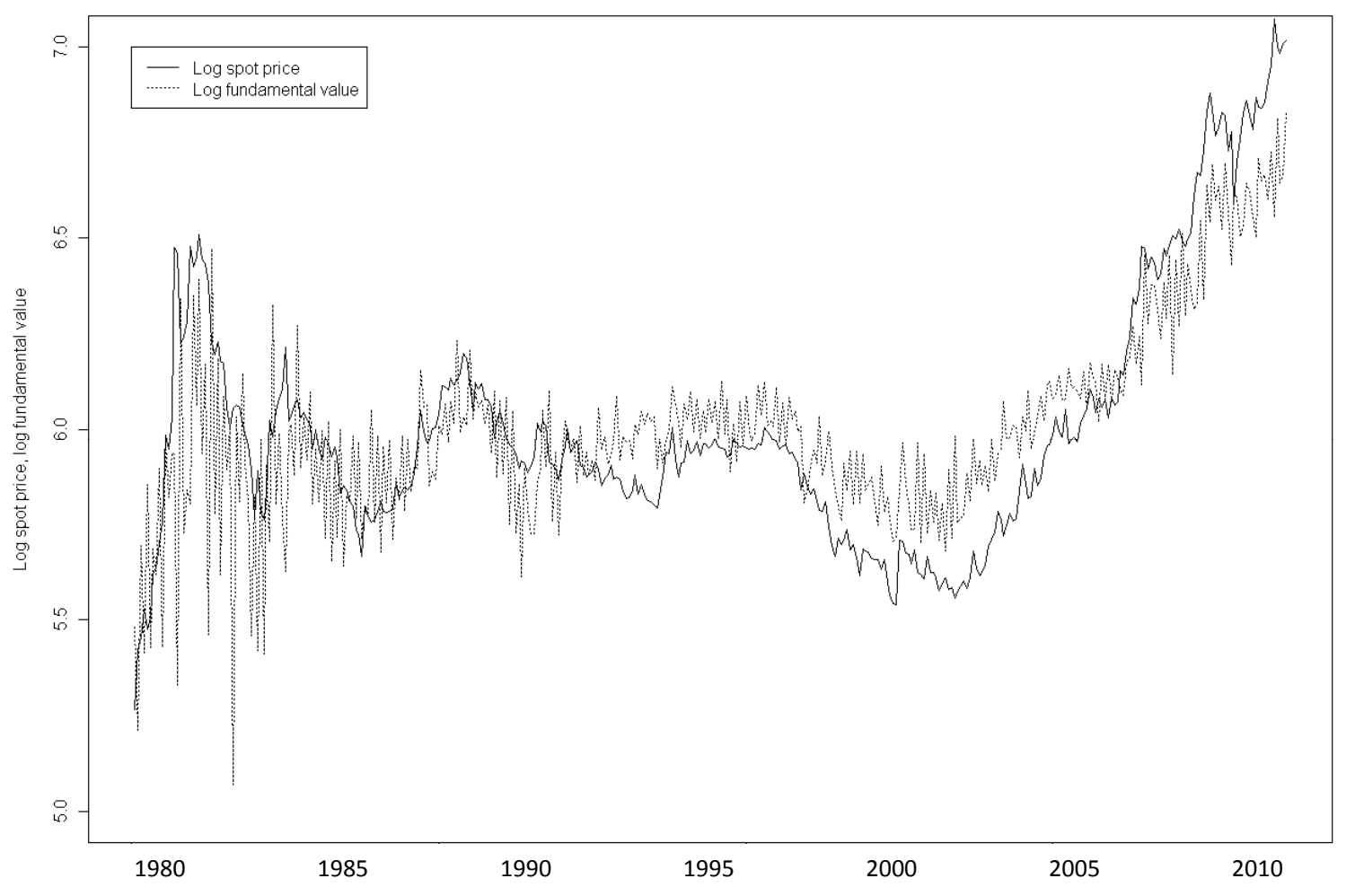

Notes: The fundamental value is calculated by using the OLS estimates from the model in eq. (3) and the convenience yield time series. The convenience yield time series is based on the first-day-of-delivery-month criterion with the understanding that results are qualitatively the same once we use the liquidity-peak criterion. 
Figure 5: Real spot price and fundamental value (in logs)

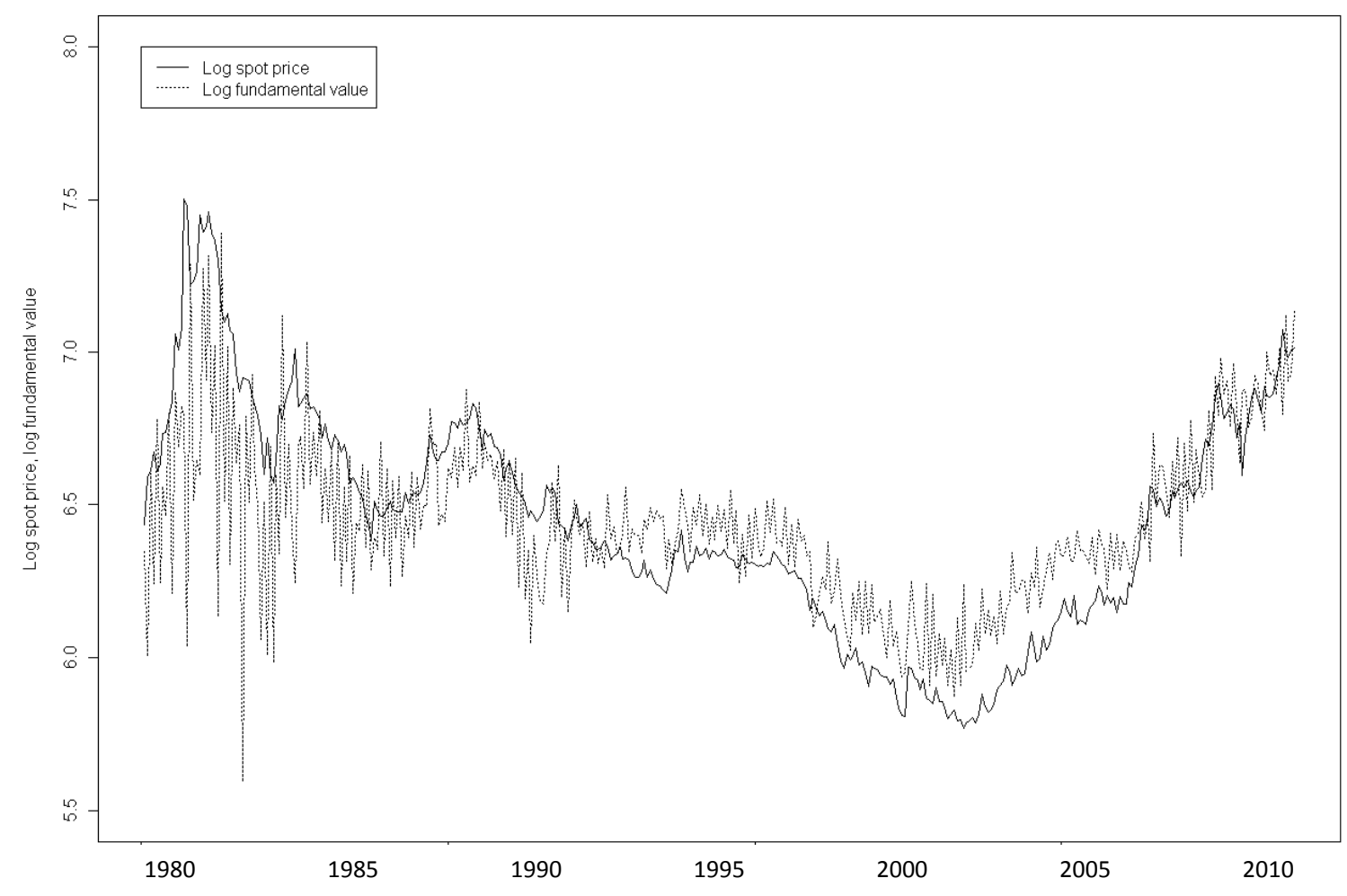

Notes: The fundamental value is calculated by using the OLS estimates from the model in eq. (3) and the convenience yield time series. The convenience yield time series is based on the first-day-of-delivery-month criterion with the understanding that results are qualitatively the same once we use the liquidity-peak criterion. 
Figure 6: Filter and smoothed probabilities, and residuals of the long-run relationship (based on nominal data)
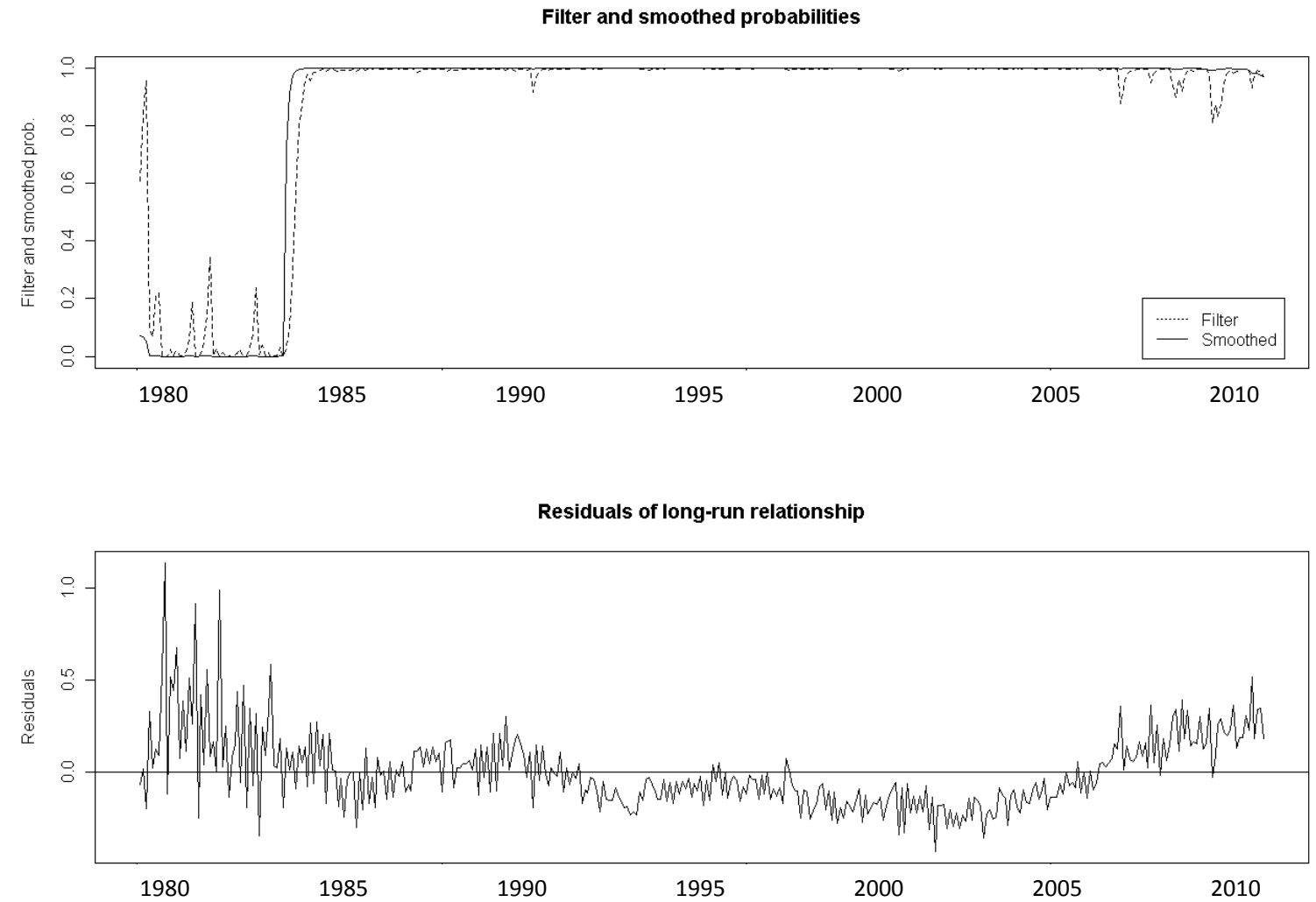

Notes: In the upper part, filter and smoothed probabilities are based on the ML estimates from the model in eq. (4) with $p=5$. In the lower part, residuals are obtained from the regression in eq. (3), drawing on nominal data, with the convenience yield time series based on the first-day-of-delivery-month criterion. With respect to both parts, results are qualitatively the same once we generate the convenience yield time series based on the liquidity-peak criterion. 
Figure 7: Filter and smoothed probabilities, and residuals of the long-run relationship (based on real data)
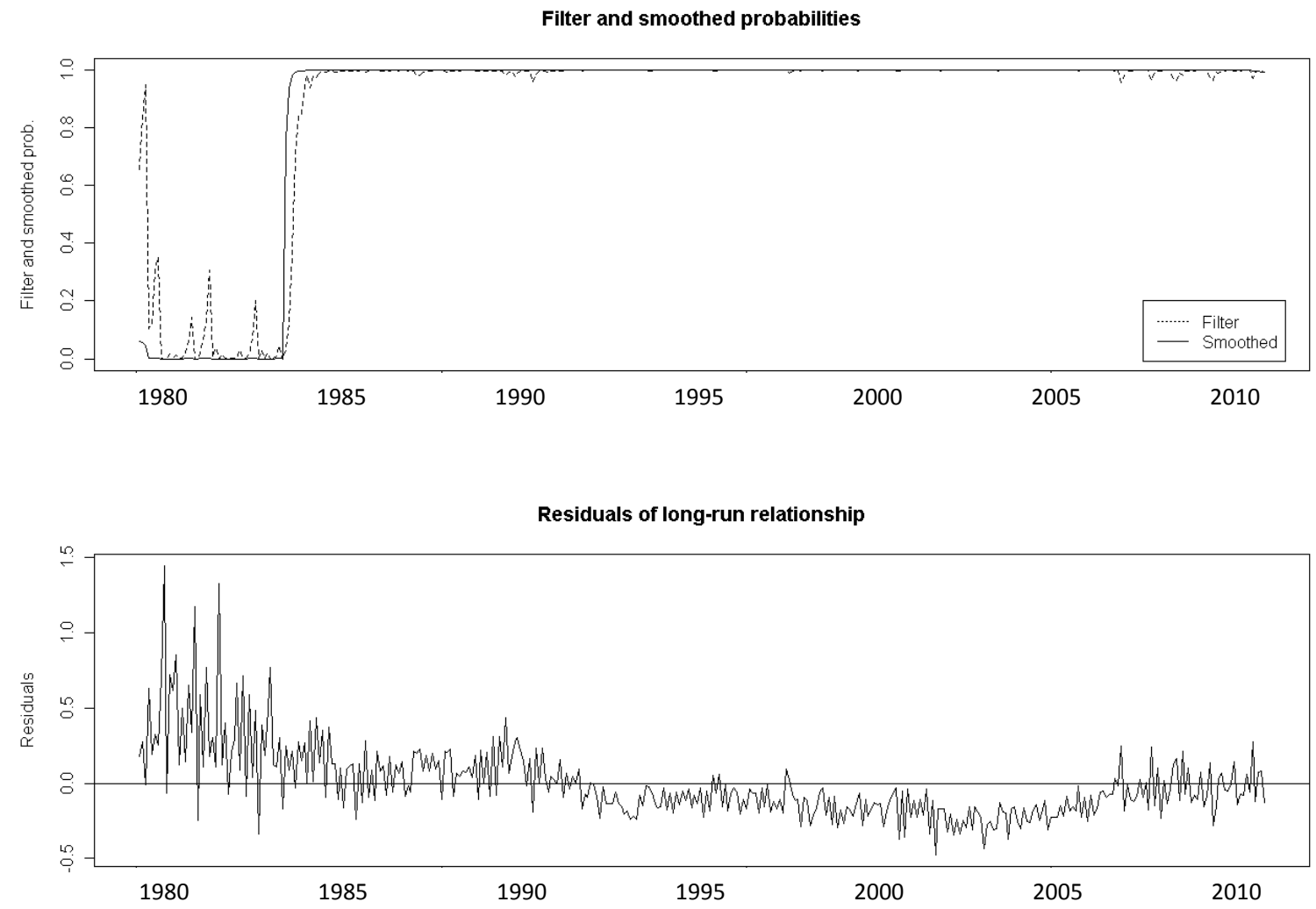

Notes: In the upper part, filter and smoothed probabilities are based on the ML estimates from the model in eq. (4) with $p=5$. In the lower part, residuals are obtained from the regression in eq. (3), drawing on real data, with the convenience yield time series based on the first-day-of-delivery-month criterion. With respect to both parts, results are qualitatively the same once we generate the convenience yield time series based on the liquidity-peak criterion. 
Table 1: Summary statistics and regression results

Panel (A): Summary Statistics

\begin{tabular}{llllllll}
\hline & Mean & Stdv. & $25 \%$ & Median & $75 \%$ & ADF & KPSS \\
\hline Nominal & & & & & & & \\
$\ln \left(P_{t}\right)$ & - & - & - & - & - & -0.9779 & $0.5669^{* *}$ \\
$\Delta \ln \left(P_{t}\right)$ & 0.0047 & 0.0564 & -0.0237 & 0.0000 & 0.0283 & $-20.0750^{* * *}$ & 0.1941 \\
$\ln \left(D_{t}\right)$ & - & - & - & - & - & -0.1376 & $1.2009^{* * *}$ \\
$\Delta \ln \left(D_{t}\right)$ & 0.0059 & 0.3557 & -0.1708 & 0.0018 & 0.1960 & $-14.6056^{* * *}$ & 0.1392 \\
& & & & & & & \\
Real & & & & & & & \\
$\ln \left(P_{t}\right)$ & - & - & - & - & - & -1.0454 & $0.9660^{* * *}$ \\
$\Delta \ln \left(P_{t}\right)$ & 0.0015 & 0.0559 & -0.0263 & -0.0027 & 0.0260 & $-20.1711^{* * *}$ & 0.2464 \\
$\ln \left(D_{t}\right)$ & - & - & - & - & - & -0.8214 & $0.4471^{*}$ \\
$\Delta \ln \left(D_{t}\right)$ & 0.0028 & 0.3556 & -0.1725 & 0.0020 & 0.1896 & $-11.2481^{* * *}$ & 0.1733 \\
& & & & & \\
\hline
\end{tabular}

Notes: Panel (A) reports basic summary statistics for the variables used in our study. The $\mathrm{ADF}$ test statistics for the null hypothesis of unit root presence are reported in the penultimate column. MacKinnon one-sided $p$-values have been used to gauge the statistical significance of these tests. The final column gives KPSS test statistics for the null hypothesis that the considered time series are stationary. ${ }^{* * *},{ }^{* *}$ and ${ }^{*}$ denote statistical significance at $1 \%, 5 \%$ and $10 \%$, respectively. Panel (B) shows results for the regression in eq. (3) and $R^{2}$ denotes the coefficient of determination. With respect to both panels, the convenience yield series are based on the first-day-of-delivery-month criterion with the understanding that results are qualitatively the same once we use the liquidity-peak criterion. 
Table 2: Markov regime-switching ADF test

\begin{tabular}{lrlrl}
\hline & $S_{t}=0$ & & $S_{t}=1$ & \\
\hline & Coef. & t-value & Coef. & \multicolumn{1}{c}{-value } \\
\hline Nominal & & & & \\
$\widehat{\rho}_{0, S_{t}}$ & 0.1495 & $9.4100^{* * *}$ & 0.0011 & 0.2249 \\
$\widehat{\rho}_{1, S_{t}}$ & -0.6553 & $-5.5516^{* * *}$ & -0.0364 & -0.9967 \\
$\widehat{\beta}_{1, S_{t}}$ & -0.4730 & -2.3469 & -0.8867 & $-14.2272^{* * *}$ \\
$\widehat{\beta}_{2, S_{t}}$ & -0.3188 & -1.2845 & -0.5093 & $-6.6351^{* * *}$ \\
$\widehat{\beta}_{3, S_{t}}$ & -0.4104 & -1.6991 & -0.4911 & $-6.5740^{* * *}$ \\
$\widehat{\beta}_{4, S_{t}}$ & -0.1547 & -0.6814 & -0.2112 & $-3.0082^{* * *}$ \\
$\widehat{\beta}_{5, S_{t}}$ & -0.1039 & -0.6253 & -0.1748 & $-3.4002^{* * *}$ \\
$\widehat{\sigma}_{S_{t}}$ & 0.2757 & & 0.0852 & \\
$\widehat{p}_{00}, \widehat{p}_{11}$ & 0.9928 & & 0.9975 & \\
$\mathrm{~L}$ & 322.63 & & & \\
& & & & \\
Real & & & & \\
$\widehat{\rho}_{0, S_{t}}$ & 0.3095 & $15.5228^{* * *}$ & -0.0075 & -1.2289 \\
$\widehat{\rho}_{1, S_{t}}$ & -0.8482 & $-5.9631^{* * *}$ & -0.1016 & -2.3259 \\
$\widehat{\beta}_{1, S_{t}}$ & -0.3443 & -1.6796 & -0.8619 & $-13.6947^{* * *}$ \\
$\widehat{\beta}_{2, S_{t}}$ & -0.2389 & -0.9689 & -0.5158 & $-6.8133^{* * *}$ \\
$\widehat{\beta}_{3, S_{t}}$ & -0.3735 & -1.5674 & -0.5176 & $-7.0728^{* * *}$ \\
$\widehat{\beta}_{4, S_{t}}$ & -0.1796 & -0.8025 & -0.2499 & $-3.6366^{* * *}$ \\
$\widehat{\beta}_{5, S_{t}}$ & -0.1292 & -0.7897 & -0.2017 & $-4.0165^{* * *}$ \\
$\widehat{\sigma}_{S_{t}}$ & 0.3264 & & 0.1002 & \\
$\widehat{p}_{00}, \widehat{p}_{11}$ & 0.9931 & & 0.9976 & \\
$\mathrm{~L}$ & 262.51 & & & \\
\hline
\end{tabular}

Notes: Results are shown for the regression in eq. (4) with $p=$ 5. The data used here are the residuals from the regression in eq. (3) with the convenience yield time series based on the first-dayof-delivery-month criterion. Results are qualitatively the same once we use the liquidity-peak criterion. ${ }^{* * *},{ }^{* *}$ and ${ }^{*}$ denote statistical significance at the $1 \%, 5 \%$ and $10 \%$ level, respectively. All tests are two-sided except for $\widehat{\rho}_{1, S_{t}}$, which is left-tailed (right-tailed) for the smaller (bigger) coefficient. Critical values are obtained by using a parametric bootstrap algorithm developed by PSARADAKIS (1998). $\mathrm{L}$ denotes the maximum of the log-likelihood function. 